Review Article : Open Access

\title{
Cockroach Allergy, Respiratory Allergic Diseases and Its Immunotherapy
}

\section{Öner Özdemir*}

\author{
Department of Pediatrics, Division of Allergy and Immunology, Hospital of Sakarya University, Türkey
}

*Corresponding author: Öner Özdemir, Professor of Pediatrics, Department of Pediatrics, Division of Allergy and Immunology, Research and Training, Hospital of Sakarya University, Adapazarı, Sakarya, Türkey, Tel: + 90-264444-54-00, Fax: +90-264-275-91-92, E-mail: onerozdemir@sakarya.edu.tr

\begin{abstract}
Cockroaches, generally found in urban homes worldwide, are known to be vectors of various infectious diseases. The most common domiciliary cockroach species are Blattella germanica (German cockroach) and Periplaneta americana (American cockroach). These two species, GC and AC have been the center of cockroach allergyrelated research. Tropomyosin is an important major allergenic cockroach protein involved in cross-reactivity among insects, mites, crustaceans, mollusks, and parasites. Structural homology between tropomyosins from cockroaches and crustaceans may explain clinical cases with the oral allergy syndrome in cockroach allergic patients consuming crustaceans e.g. shrimp. Several reports and a meta-analysis also revealed that current infection with Ascaris might be associated with a significant increased risk of asthma. Cockroach allergen-derived proteases play a direct role on airway epithelial as well as dendritic cells thru activation of the protease activated receptor (PAR)-2. Cockroach-derived proteases lead to an increased penetration of cockroach allergen thru disturbing airway epithelial integrity, which can activate innate immune cells (e.g., dendritic cells) via binding to Toll-like receptor or C-type lectin receptors. The activated dendritic cells promote the adaptive immune system cells to a Th2 cell response and subsequently increase risk of sensitization. HLA-DRB1 ${ }^{*} 01$ alleles are considered to be associated with sensitization to cockroach allergens. Respiratory allergic diseases such as asthma and rhinitis are the most common diseases associated with cockroach infestation of houses in the USA and other parts of the world. The high prevalence of patients with asthma has $\lg E$ to cockroach allergens have been reported in several urban or inner cities around the world. Cockroach sensitivity is reported as $30 \%$ in Africa, 30\% in India, 6-29\% in European countries. Early exposure to cockroach in children of atopic parents may increase the risk of developing asthma. Patients with cockroach allergy have particularly high levels of serum IgE antibodies and steroid dependency as compared to general asthmatics patients. Cockroach allergen exposure appears to have a greater effect on asthma morbidity than that of dust mite or pet allergen among inner-city children with asthma. The effective preventive approach combines the pesticide application, family education and physical elimination of hiding places. Although immunotherapy for cockroach allergy may be effective, further randomized controlled clinical trials with larger number of patients and longer follow-up and using wellcharacterized cockroach extracts are required.
\end{abstract}

\section{Keywords}

Cockroach, Blattella germanica, Periplaneta americana, Allergy, Asthma, Rhinitis, Immunotherapy.

\section{Introduction}

Cockroaches, commonly found in urban dwellings worldwide, are known to be vectors of various infectious diseases [1]. The most common domiciliary cockroach species are Blattella germanica (Bla g; German cockroach: GC) and Periplaneta americana (Per a; American cockroach: AC). These two species, GC and AC have been the center of cockroach allergy-related research. GC is a small cockroach, approximately three quarters of an inch in length, which commonly infests houses in the USA. AC is a large cockroach, approximately 2 inches in length that infests houses, schools, hospitals, and other large buildings. AC is less fertile than $\mathrm{GC}$, requires higher temperatures $\left(\sim 27^{\circ} \mathrm{C}\right)$ and humidity for optimal population growth. GC is commonly found in cool and dry climates such as Europe and USA, whereas the larger AC (35-53 mm vs. 16 $\mathrm{mm}$ in length) prefers hot and humid conditions such as tropical countries e.g. Thailand, Taiwan and Brazil [2].

\section{Other Cockroach Species and their Contribution to Indoor Allergens}

Among 4.500 known species of cockroaches only 5, the AC, GC, Oriental (Blatta orientalis), dusky or smokey brown (Periplaneta fuliginosa) and brown-banded (Supella longipalpis) varieties, are frequently found in homes and they potentially contribute to indoor allergens. Aerosolized proteins derived from their saliva, fecal materials, secretions, cast skins, debris and dead bodies of cockroaches produce indoor allergens and they can induce IgEmediated hypersensitivity reactions and allergic disorders [3].

\section{Cockroach Allergens and Co-Sensitization}

The only cross-reactive allergens that have so far been sequenced from both AC and GC are the group 1 allergens Bla g 1 and Per a 1 [4]. However, Tropomyosin is an important major allergenic cockroach protein involved in cross-reactivity among insects, mites, crustaceans, mollusks, and parasites. It has also been found as a major allergen in shrimp (Pen a 1, Met e 1, Pen I 1) and also in other crustaceans (crab Cha f 1, lobster Pan s 1, Hom a 1), mollusks (oyster Cra g 1, gastropod Tur c 1, Tod p 1) and dust mites (Der p 10, Der f 10) $[3,4]$.

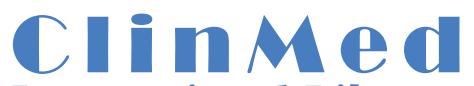

International Library
Citation: Özdemir Ö (2014) Cockroach Allergy, Respiratory Allergic Diseases and Its Immunotherapy. Int J Immunol Immunother. 1:002

Received: December 20, 2014: Accepted: December 30, 2014: Published: December 31, 2014

Copyright: () 2014 Özdemir Ö. This is an open-access article distributed under the terms of the Creative Commons Attribution License, which permits unrestricted use, distribution, and reproduction in any medium, provided the original author and source are credited. 
AC tropomyosin, designated as Per a 7, reacts with approximately $50 \%$ of sera from asthmatic children allergic to cockroaches [3]. The sequence of a GC tropomyosin with greater than $98 \%$ amino acid sequence identity to AC tropomyosin has been recently reported. This allergen shows a high degree of sequence identity to tropomyosins from invertebrates, particularly from mites ( $80 \%$ identity) and shrimp ( $82 \%$ identity). Structural homology between tropomyosins from cockroaches and crustaceans may explain clinical cases with the oral allergy syndrome in cockroach allergic patients consuming crustaceans e.g. shrimp [5].

Co-sensitization to dust mite allergens in cockroach-sensitized individuals is a common feature, as shown in earlier reports. Since cockroach and dust mites usually share the same indoor environments and some major allergens, these mechanisms could justify such a high prevalence of co-sensitization. It is possible that the high frequency of reactivity to cockroach tropomyosin seen in some countries such as Brazil reflects cross-reactivity to mite tropomyosin, which shares $80 \%$ sequence identity to the cockroach homolog $[2,3]$. However, cosensitization to both tropomyosins from different origin cannot be ruled out as well.

It has been assumed that the high frequency of sensitization to tropomyosins in Brazil and Africa maybe due to cross-reactivity to tropomyosin from parasites in guts. Tropomyosins from parasites including Ascaris, Filaria and Anisakis simplex show approximately $70 \%$ amino acid sequence identity to tropomyosins from dust mites and cockroaches [2-4]. Recombinant Ascaris tropomyosin was shown to bind IgE from patients with asthma and/or rhinitis in $42-68 \%$ of patients from Colombia and Brazil [6]. Strong correlation was found for IgE antibodies to tropomyosins from Ascaris and $\mathrm{AC}$ in sera from children living in a parasite-endemic area and from patients with cockroach allergy. IgE responses to inhaled tropomyosin allergens develop easily as a result of previous sensitization to Ascaris tropomyosin, triggering persistent lung inflammation. Infection with Ascaris may indirectly promote development of allergy and asthma. Consistent with this, several reports and a meta-analysis revealed that current infection with Ascaris was associated with a significant increased risk of asthma. In poor countries, where frequency of parasite infections is much higher, this effect would play a significant role $[7,8]$.

\section{Cockroach Allergy Prevalence in Respiratory Allergic Diseases}

The high prevalence of patients with asthma has IgE to cockroach allergens have been reported in several urban or inner cities around the world. Cockroach sensitivity is reported as 30\% in Africa, $30 \%$ in India, $6-29 \%$ in European countries, while in Turkey, it is found as $2-51 \%$ in studies from different cities of the country [9].

In the USA and Latin America, the prevalence of cockroach allergy ranges from $17 \%$ to $59 \%$ in various studies involving both children and adults. In Washington, DC, 28\% of 114 unselected allergy patients had positive allergy skin prick test (SPT) to GC extract, compared with only $7.5 \%$ of 253 healthy control subjects [10]. In New York City, $44 \%$ of 589 patients seen at hospital based allergy clinics had positive SPT reactions to GC extract. Analysis by ethnic subgroup revealed striking variation in the prevalence of SPT reactivity to cockroach extract, with a prevalence of $59 \%$ among Puerto Rican patients [11]. National Cooperative Inner-City Asthma Study (NCICAS) indicated that $36 \%$ of 1,286 asthmatic children living in low income communities in 6 northeastern USA cities had a positive allergy SPT to GC extract [12]. 55\% of children and young adults with asthma, rhinitis, or both living in Brazil had positive SPT responses to cockroach allergen [13].

Cockroach allergy is less frequent in European than in American children. European studies on children and adults attending an allergy clinic show a high variability in cockroach sensitization varying from $4 \%$ to $26 \%[9,14]$. In a research studying cockroach sensitivity in Norway, 31 subjects ( $7.5 \%)$ were sensitized (5 mono-sensitized) to cockroach (27 subjects by SPT and 7 subjects by IgE antibody, all with additional inhalant allergy). Reported allergic diseases in cockroach-sensitized subjects of this study were asthma and rhinitis (n:10), asthma only (n:9), rhinitis only (n:2) and neither asthma nor rhinitis (n:10) [15]. In Madrid of Spain, 15\% of asthmatic atopics areas are sensitive to cockroaches [16].

The prevalence of cockroach sensitization in Far East countries was reported to be $43-58 \%$ in Taiwan and $23 \%$ in Hong Kong [17]. In a study participating 6304 patients from 25 allergy centers across China, $26 \%$ of patients were SPT positive to the AC and 19\% SPT positive to the GC. The prevalence of positive cockroach SPT was higher in southern than in northern China, higher in adults than in children, and higher in males than in females. Of the SPT positive patients, $88 \%$ were also SPT positive to dust mite (Dermatophagoides pteronyssinus) as well [18]

\section{Cockroach Exposure, Development of Sensitization and Respiratory Allergic Diseases}

Early exposure to cockroach in children of atopic parents may increase the risk of developing asthma. A more recently prospective study has demonstrated a significant association between exposure to cockroach allergens in the first 3 months of life and the development of repeated wheeze in the first year among infants in metropolitan Boston [19]. A survey of over 400 children with asthma from 8 US urban areas, Rosenstreich et al. found that high bedroom levels of the cockroach allergen Bla g 1 were related to asthma morbidity if the children living there who were also sensitized to cockroaches [20].

Cockroach exposure is detected by measuring the levels of major allergens Bla g 1 and Bla g 2 / g of dust in living and/or bedrooms, as markers of cockroach exposure [2]. Compared with children without exposure, those exposed to cockroach allergen levels $\geq 2 \mathrm{U} / \mathrm{g}$ of settled dust were 36 times more likely to have asthma [21]. Bla g 1 and/or Bla g 2 allergen exposure $>2 \mathrm{U} / \mathrm{g}$ of dust is thought to be a strong risk factor for cockroach sensitization. And asthma symptoms occur with increased frequency with exposure to $8 \mathrm{U} / \mathrm{g}$ of dust or more among sensitized individuals. Furthermore, cockroach allergens appear to be particularly effective at sensitizing atopic individuals. Bla g 2 was able to induce IgE production at levels of exposure 10-100 fold lower than cat and dust mite allergens. The proposed sensitizing threshold of Bla $\mathrm{g} 2$ is $0.08 \mu \mathrm{g} / \mathrm{g}$ dust $(2 \mathrm{U} / \mathrm{g})$, whereas those of mite group 1 and cat allergens are $2 \mu \mathrm{g} / \mathrm{g}$ dust and $8 \mu \mathrm{g} / \mathrm{g}$ dust, respectively [22]. As a result, cockroach allergen exposure appears to have a greater effect on asthma morbidity than that of dust mite or pet allergen among innercity children with asthma.

\section{Mechanisms of Cockroach Allergen- Induced} Sensitization

Effects of proteases from cockroach extracts on promoting disease have been observed for a long time. An increase in bronchial epithelial permeability by cockroach extracts was reported, similarly to the effect observed for dust mite proteases. Subsequently, a serine protease activity with a direct pro-inflammatory effect on respiratory epithelial cells was shown by utilizing specific inhibitors [23]. Moreover, studies on protease activated receptor (PAR)-2 deficient mice have confirmed that PAR-2 mediates allergen-derived proteases in cockroach frass-induced airway allergic inflammation [24]. The mechanism by which cockroach proteases increased IL-8 expression in human bronchial epithelial cells involved activation of PAR-2 and extracellular-signal-regulated kinase.

Cockroach allergen-associated/derived proteases play a direct role on airway epithelial as well as dendritic cells thru activation of the PAR-2. Cockroach-derived proteases lead to an increased penetration of cockroach allergen thru disturbing airway epithelial integrity, which can activate innate immune cells (e.g., dendritic cells) via binding to Toll-like receptor (TLR) or C-type lectin (CLR) receptors [25]. The activated dendritic cells promote the adaptive immune system cells to a Th 2 cell response and subsequently increase 
risk of sensitization. Therefore, proteases play a role as Th2 adjuvants in the development of allergic inflammation of human airway [26]. Cockroaches also are a source of chitin, which has proinflammatory activities and can induce cells to produce Th2 cytokines [27]. German and Oriental cockroach crude whole body extracts also have a direct effect on human eosinophils, inducing degranulation, superoxide and IL-8 production, and increased surface expression of CD11b and CD69 by the activation of PAR-2 [28]. On the other hand, genetic factors, particularly genetic variations of TLR, CLR, $\mathrm{CD} 14$, either alone or in interaction with cockroach exposure, confer the susceptibility to increased risk of cockroach sensitization and subsequently inflammation in the lung and asthma [29].

\section{Predisposition to Cockroach Allergy Development}

In a recent study, HLA-DRB $1^{\star} 01$ alleles are considered to be associated with sensitization to cockroach allergens. DRB1 ${ }^{\star} 0101$ allele in the Hutterites and the DRB $1^{\star} 0102$ allele in African Americans are shown to increase risk for cockroach sensitization [30].

Results of a recent inner-city birth cohort study showed that prenatal exposure to cockroach allergens was associated with a greater risk of sensitization by the age of 5 to 7 years. Specifically, this risk was increased by exposure to airborne nonvolatile combustion byproducts (polycyclic aromatic hydrocarbons), with children null for the Glutathione-S-transferase m 1 (GSTM1) mutation particularly vulnerable [31].

Polymorphisms in interleukin-12A were found to be related with the development of cockroach allergy in children with asthma. Among children in Childhood Asthma Management Program (CAMP), homozygosity for the minor allele of SNP rs2243151 in interleukin-12A was inversely associated with SPT reactivity to GC. And homozygosity for the minor allele of SNP rs17826053 in interleukin-12A was associated with increased risks of SPT reactivity to $\mathrm{AC}$ and to $\mathrm{GC}[32]$.

\section{Cockroach Allergy and Respiratory Allergic Diseases (Asthma and Rhinitis)}

Respiratory allergic diseases such as asthma and rhinitis are the most common diseases associated with cockroach infestation of houses in the United States and other parts of the world. Cockroach allergy has been recognized as an important cause of asthma for almost 50 years. In 1964, Bernton and Brown were the first to report positive SPT responses to cockroach allergen (44\%) in a landmark study of 755 allergy clinic patients living in New York. They also demonstrated that $13 \%$ of patients who otherwise considered as nonatopic were sensitized to cockroach allergen alone [10]. In 1979, subsequent work by Kang et al confirmed the causal relationship between cockroach allergy and asthma by showing early, late-phase, and dual bronchoconstriction after inhalation of cockroach extract by sensitized asthmatic patients [33].

Sensitization and exposure to cockroach allergens is associated with increased asthma morbidity in the USA, especially among lower socioeconomic groups, including African American and Hispanic populations. In inner-city communities of the US, researchers demonstrated that having specific IgE to cockroaches was associated with an increased risk for asthma hospitalizations and corticosteroid use in a population of asthmatic children [2,34]. Specific properties of cockroach allergens, including proteolytic activity, have been proposed to contribute to more severe disease associated with cockroach sensitization. Accordingly, cockroach allergy is an important risk factor for asthma-related emergency room visits and hospital admissions.

Recently, the National Cooperative Inner City Asthma study (NCICAS) has confirmed that the association of sensitization and exposure to cockroach allergens is a major risk factor for asthma morbidity in children from large cities in the USA. The NCICAS examined SPT sensitivity, bedroom cockroach allergen levels in dust and asthma morbidity among 476 asthmatic children. Children with the combination of a positive SPT reaction to cockroach extract and a bedroom level of Bla g $1>8 \mathrm{U} / \mathrm{g}$ of dust had significantly more hospitalizations for asthma, unscheduled medical visits and parentreported wheezing than other children [12].

\section{Distinctive Characteristics of Cockroach Asthma}

Typical characteristics are identified from cockroach-allergic patients with asthma, when compared with those with ragweed asthmatics and asthmatics in general. A history of perennial asthma, possibly worse in the winter is the most common clinical presentation of asthmatic patients with cockroach allergy. Patients with cockroach allergy have particularly high levels of serum IgE antibodies as compared to general asthmatics patients. Steroid dependency of the cockroach asthma is higher ( $32 \%$ of the patients) than those of general asthmatics. As a result, cockroach asthma is a severe allergic asthma which needs more attention and intensive investigation $[3,20,35,36]$.

\section{Diagnosis of Cockroach Allergy}

Over the last 10 years, several cockroach allergens have been identified, sequenced, and produced as biologically active recombinant proteins. However, commercial cockroach extracts used for diagnosis and treatment are still nonstandardized. Cockroach extracts manufactured in the USA for allergy diagnosis show variation in levels of major allergens Bla g 1 and Bla g 2 of up to sevenfold. Slater et al. have shown that the mean potency of $3 \mathrm{GC}$ extracts in USA was $3.300 \mathrm{BAU} / \mathrm{mL}$, whereas standardized mite, cat or grass extracts contain typically $5.000-100.000 \mathrm{BAU} / \mathrm{mL}$ [37]. In present clinical practice, diagnosis of cockroach allergy is performed by SPT and/or measurement of specific IgE to cockroach, utilizing crude extracts.

\section{Preventive and Therapeutic Approaches for Cockroach Allergy}

It has been demonstrated over the past 5 decades that the combination of cockroach allergy and cockroach exposure is one of the most important factors contributing to the high morbidity seen in inner-city children with asthma. Firstly; treatment of cockroachinduced asthma includes recommendations to reduce exposure to cockroach allergens in the home and work environments. Allergen avoidance in childhood is known to effectively reduce the prevalence of sensitization. Efforts have been made to reduce environmental allergen exposure in homes of patients with cockroach-induced asthma, which ultimately could lead to improvement of symptoms. The effective approach combines the pesticide application, family education and physical elimination of hiding places. Cockroach extermination needs to be done in all rooms and should be coupled with thorough cleaning measures, addressing reservoirs of allergen in carpets, rugs, other sites and efforts to prevent reinfestations to achieve effective control of allergen exposure in the household. Secondly; although recent studies suggest that immunotherapy for cockroach allergy may be effective, further randomized controlled clinical trials with larger number of patients and longer follow-up and using well-characterized cockroach extracts are required.

Both preventive and therapeutic applications for cockroach allergy and/or - related disorders are discussed in detail below.

\section{Cockroach Allergy Prevention}

Strategies for decreasing environmental exposure to cockroach allergens in inner-city homes have recently been investigated. However, cockroach extermination alone was not reported to reduce sufficiently the allergen levels in house dust. The results suggest that a sustained decrease in cockroach allergen levels is difficult to accomplish, even after successful extermination of cockroach populations. Recently, it was demonstrated that it was possible to significantly reduce the cockroach infestation (allergen source) below the cockroach sensitization threshold $(2 \mathrm{U} / \mathrm{g})$ in bed and below the asthma morbidity threshold $(8 \mathrm{U} / \mathrm{g})$ on bedroom and living room floor/sofas, even in multifamily dwellings only by integrated pest 
management combined with pesticide application, family education and structural elimination of hiding places [38]. Cockroach allergens may persist in the environment up to several months following eradication of the insects. Researchers from the Inner City Asthma Studies (ICAS) were the first to demonstrate that environmental interventions could effectively reduce asthma symptoms. One year of a comprehensive controlled intervention strategy including professional cleaning, bait traps, insecticides and HEPA filters could reduce cockroach allergen levels. This change significantly correlated with decreased wheeze and less nighttime asthma symptoms and fewer schooldays misses. This clinical improvement lasts for 1 year after the monitored intervention ended. The study demonstrated that continuous efforts might be necessary for sustained cockroach allergen reduction. Therefore, this strategy may not be feasible in real life conditions $[2,39]$

As mentioned above, cockroach allergens persist in the indoor environment, even after the cockroach population has been greatly reduced. Intervention based on professional extermination with abamectin resulted in a decrease in Bla $\mathrm{g} 1$ levels in the kitchen, although only for a short time. The reduction achieved to levels was still above those thought as clinically significant. More recently, Eggleston et al have studied the effect of professional extermination with $0.05 \%$ abamectin and house cleaning on cockroach infestation and allergen levels in inner city homes of Baltimore. Although such measures resulted in a cockroach population decrease and a substantial reduction of allergen levels in some homes, levels at the end of the 8-month study period were still above $20 \mathrm{U}$ of Bla $\mathrm{g} 1 / \mathrm{g}$ in most homes [40]. Similarly, Williams et al have also demonstrated successful cockroach extermination with hydramethylnon; however, elevated Bla g 1 and Bla g 2 levels continued for up to 6 months after use [41]. These studies showed that the current pesticides applied by professional pest control technicians can be effective. However, constant removal of cockroach allergens from homes may be difficult to attain.

\section{Cockroach Allergen Immunotherapy}

Commercial cockroach extracts used for immunotherapy remain nonstandardized, and well-designed controlled studies exploring the role of specific immunotherapy in the treatment of patients with cockroach allergy are lacking. Manufactured GC allergen extracts in USA are of low and variable potency such as glycerinated GC extracts had potencies of $1.000 \mathrm{BAU} / \mathrm{mL}$. Although still low in potency, it should be possible to achieve therapeutic immunotherapy doses (100-2.500 BAU) utilizing any of these extracts [42]. The allergen immunotherapy practice parameter (AIPP) third update provides new dosing recommendations for nonstandardized extracts distinguishing between pollen $(0.5 \mathrm{~mL}$ of a 1:100 or 1:200 vol $/ \mathrm{vol})$ and cockroach (highest tolerated dose) extracts. And other extracts such as grass and tree pollens should be known to be unstable after mixing with cockroach extracts by practicing allergists $[43,44]$.

Immunotherapy with cockroach extract has been reported to lead to beneficial changes in immunologic and clinical parameters in one small study carried out in 1988. Currently, cockroach allergen immunotherapy is not considered to have proven efficacy. Success in immunotherapy with natural allergenic products may be improved with the use of standardized extracts, and the development of standardized cockroach extracts is currently being pursued by the FDA. 2013 AAAAI recommendation in Practice Parameter stated that cockroach allergen immunotherapy can be considered; however, it has only been evaluated in a limited number of studies, an effective dose is not known, and it is not clear how effective the treatment is for respiratory allergic diseases such as in asthma or rhinitis (evidence category: C; and evidence quality: Optional) [45].

Cockroach allergen immunotherapy has been also practiced using crude, non-standardized extracts, and its effectiveness is not established. There have been very few reports of immunotherapy for cockroach allergy. In a study performed by Kang et al. in 1988, involving a small number of patients, immunotherapy with cockroach extract resulted in beneficial changes in immunological and clinical parameters, including symptoms and medication use, after 5 years of treatment. In this study, subcutaneous mixed cockroach (German, American and Oriental) immunotherapy was performed among 28 cockroach-sensitive asthma patients. The 'active treatment' group received immunotherapy with cockroach extract (a cumulative dose of 65.600 protein nitrogen units over the 60 -month trial) in addition to other inhalant allergens. The 'control' group received immunotherapy with all relevant allergens except cockroach allergens. Those receiving cockroach extract had reduced symptom plus medication scores, an increase in cockroach-specific blocking antibody and blunted invitro basophil histamine release after receiving 5 years of cockroach allergen immunotherapy. However, a limitation of this study was that although $11 / 15$ subjects in the active group completed the study, only $2 / 13$ receiving control injections did so [46].

In 2011, a double-blind, placebo controlled cockroach immunotherapy trial from India by Srivastava et al has been reported. Immunotherapy was carried out using an in-house AC extract, prepared under good manufacturing practice conditions, and 50 cockroach allergic patients with asthma and/or rhinitis were enrolled, of whom 42 (28 actively treated, 18 placebo) completed the first year of the study. Forty-two patients completed 1 year of immunotherapy with a $1 \mathrm{ml}$ volume maintenance dose of an aqueous extract containing $3 \mathrm{mg} / \mathrm{ml}$ of protein from AC. Results at one year of therapy, while patients were still on build-up phase, showed significant improvement in clinical scores and bronchial hyper-reactivity, and increase in cockroach specific IgG4. Unfortunately, the study did not include placebo-treated subjects in its second year, and only 12 patients in the active treatment group provided samples for analysis. After 2 years of immunotherapy, there was significant reduction in symptoms and medication use as well as a reduction in specific $\operatorname{IgE}$ and increase in cockroach-specific IgG4. Other limitations of this study contain little information on how symptom and medication scores were developed, and lack of information on adverse reactions to allergen immunotherapy [47].

In 2014, Wood et al conducted four pilot studies: (1) an open-label study to assess the safety of cockroach sublingual immunotherapy (SLIT) in adults and children; (2) a randomized, double-blind biomarker study of cockroach SLIT vs. placebo in adults; (3) a randomized, double-blind biomarker study of 2 doses of cockroach SLIT vs. placebo in children; and (4) an open-label safety and biomarker study of cockroach subcutaneous immunotherapy (SCIT) in adults. The adult SLIT trial (n:54; age:18-54 years) found a significantly greater increase in cockroach-specific IgE levels between the active and placebo groups and a trend toward increased cockroach-specific IgG4 levels in actively treated subjects, but no evidence of functional blocking antibody response. The SLIT trial in children (n:99; age:5-17 years) found significant differences in IgE, IgG, and IgG4 responses between both active groups and the placebo group, but no consistent differences between the high- and low-dose groups. In the adult SCIT study, the treatment resulted in significant changes from baseline in cockroach IgE, IgG4, and blocking antibody levels. The authors concluded that the administration of cockroach allergen by means of SCIT is immunologically more active than SLIT, especially with regard to IgG4 levels and blocking antibody responses. No safety concerns were raised in any age group. These 4 pilot studies suggest that cockroach allergen immunotherapy is more likely to be effective using SCIT [48].

Although these studies suggest that cockroach immunotherapy may be effective, further randomized controlled clinical trials with larger number of patients and longer follow-up, and using wellcharacterized cockroach extracts will be required to establish efficacy and safety of this form of treatment.

\section{References}

1. Tatfeng YM, Usuanlele MU, Orukpe A, Digban AK, Okodua M, et al. (2005) Mechanical transmission of pathogenic organisms: the role of cockroaches. $J$ Vector Borne Dis 42: 129-134. 
2. Pomés A, Arruda LK2 (2014) Investigating cockroach allergens: aiming to improve diagnosis and treatment of cockroach allergic patients. Methods 66 75-85

3. Arruda LK, Vailes LD, Ferriani VP, Santos AB, Pomés A, et al. (2001) Cockroach allergens and asthma. J Allergy Clin Immunol 107: 419-428.

4. Wu CH, Lee MF (2005) Molecular characteristics of cockroach allergens. Cell Mol Immunol 2: 177-180.

5. Purohit A, Shao J, Degreef JM, van Leeuwen A, van Ree R, et al. (2007) Role of tropomyosin as a cross-reacting allergen in sensitization to cockroach in patients from Martinique (French Caribbean island) with a respiratory allergy to mite and a food allergy to crab and shrimp. Eur Ann Allergy Clin Immuno 39: $85-88$.

6. Santos AB, Rocha GM, Oliver C, Ferriani VP, Lima RC, et al. (2008) Cross reactive IgE antibody responses to tropomyosins from Ascaris lumbricoides and cockroach. J Allergy Clin Immunol 121: 1040-1046.

7. Takeuchi H, Zaman K, Takahashi J, Yunus M, Chowdhury HR, et al. (2008) High titre of anti-Ascaris immunoglobulin $\mathrm{E}$ associated with bronchial asthma symptoms in 5-year-old rural Bangladeshi children. Clin Exp Allergy 38: 276 282.

8. Santiago Hda C, Ribeiro-Gomes FL2, Bennuru S2, Nutman TB2 (2015) Helminth Infection Alters IgE Responses to Allergens Structurally Related to Parasite Proteins. J Immunol 194: 93-100.

9. Uzel A, Capan N, Canbakan S, Yurdakul AS, Dursun B (2005) Evaluation of the relationship between cockroach sensitivity and house-dust-mite sensitivity in Turkish asthmatic patients. Respir Med 99: 1032-1037.

10. BERNTON HS, BROWN H (1964) INSECT ALLERGY--PRELIMINARY STUDIES OF THE COCKROACH. J Allergy 35: 506-513

11. Bernton HS, Brown H (1967) Cockroach allergy II: the relation of infestation to sensitization. South Med J 60: 852-855.

12. Eggleston PA, Rosenstreich D, Lynn H, Gergen P, Baker D, et al. (1998) Relationship of indoor allergen exposure to skin test sensitivity in inner-city children with asthma. J Allergy Clin Immunol 102: 563-570.

13. Santos AB, Chapman MD, Aalberse RC, Vailes LD, Ferriani VP, et al. (1999) Cockroach allergens and asthma in Brazil: identification of tropomyosin as a major allergen with potential cross-reactivity with mite and shrimp allergens. J Allergy Clin Immunol 104: 329-337.

14. Van Gysel D, Govaere E, Doli E, De Baets F (2006) Cockroach sensitisation in Belgian children. Eur J Pediatr 165: 662-664.

15. Lødrup Carlsen KC, Carlsen KH, Buchmann MS, Wikstrøm J, Mehl R; GAIN (2002) Cockroach sensitivity in Norway: a previously unidentified problem? Allergy 57: 529-533.

16. Pola J, Valdivieso R, Zapata C, Moneo I, Duce F, et al. (1988) Cockroach hypersensitivity in asthmatic patients. Allergol Immunopathol (Madr) 16: 105 107

17. Tsai JJ, Kao MH, Wu CH (1998) Hypersensitivity of bronchial asthmatics to cockroach in Taiwan. comparative study between American and German cockroaches. Int Arch Allergy Immunol 117: 180-186.

18. Sun BQ, Lai XX, Gjesing B, Spangfort MD, Zhong NS (2010) Prevalence of sensitivity to cockroach allergens and IgE cross-reactivity between cockroach and house dust mite allergens in Chinese patients with allergic rhinitis and asthma. Chin Med J (Engl) 123: 3540-3544.

19. Finn PW, Boudreau JO, He H, Wang Y, Chapman MD, et al. (2000) Children at risk for asthma: home allergen levels, lymphocyte proliferation, and wheeze. J Allergy Clin Immunol 105: 933-942.

20. Rosenstreich DL, Eggleston P, Kattan M, Baker D, Slavin RG, et al. (1997) The role of cockroach allergy and exposure to cockroach allergen in causing morbidity among inner-city children with asthma. N Engl J Med 336: 13561363.

21. Litonjua AA, Carey VJ, Burge HA, Weiss ST, Gold DR (2001) Exposure to cockroach allergen in the home is associated with incident doctor-diagnosed asthma and recurrent wheezing. J Allergy Clin Immunol 107: 41-47.

22. Platts-Mills TA, Vervloet D, Thomas WR, Aalberse RC, Chapman MD (1997) Indoor allergens and asthma: report of the Third International Workshop. $J$ Allergy Clin Immunol 100: S2-24.

23. Lee MF, Chang CW, Wang NM, Lin SJ, Chen YH (2014) Serine protease inhibitor gabexate mesilate attenuates american cockroach-induced bronchia damage and inflammatory cytokine release. J Investig Allergol Clin Immunol 24: 338-345.

24. Page K, Lierl KM, Herman N, Wills-Karp M (2007) Differences in susceptibility to German cockroach frass and its associated proteases in induced allergic inflammation in mice. Respir Res 8: 91.

25. Yang $\mathrm{H}$, Kong $\mathrm{X}$, Wei J, Liu C, Song $\mathrm{W}$, et al. (2012) Cockroach allergen Per a 7 down-regulates expression of Toll-like receptor 9 and IL-12 release from P815 cells through PI3K and MAPK signaling pathways. Cell Physiol
Biochem 29: 561-570.

26. Sudha VT, Arora N, Singh BP (2009) Serine protease activity of Per a 10 augments allergen-induced airway inflammation in a mouse model. Eur $\mathrm{J}$ Clin Invest 39: 507-516.

27. Burton OT, Zaccone $P$ (2007) The potential role of chitin in allergic reactions Trends Immunol 28: 419-422.

28. Sohn MH, Lee YA, Jeong KY, Sim S, Kim KE, et al. (2004) German cockroach extract induces activation of human eosinophils to release cytotoxic inflammatory mediators. Int Arch Allergy Immunol 134: 141-149.

29. Gao P (2012) Sensitization to cockroach allergen: immune regulation and genetic determinants. Clin Dev Immunol 2012: 563760

30. Donfack J, Tsalenko A, Hoki DM, Parry R, Solway J, et al. (2000) HLADRB1*01 alleles are associated with sensitization to cockroach allergens. $J$ Allergy Clin Immunol 105: 960-966.

31. Perzanowski MS, Chew GL, Divjan A, Jung KH, Ridder R, et al. (2013) Early-life cockroach allergen and polycyclic aromatic hydrocarbon exposures predict cockroach sensitization among inner-city children. J Allergy Clin Immunol 131: 886-893.

32. Pistiner M, Hunninghake GM, Soto-Quiros ME, Avila L, Murphy A, et al (2008) Polymorphisms in IL12A and cockroach allergy in children with asthma. Clin Mol Allergy 6: 6.

33. Kang B, Vellody D, Homburger H, Yunginger JW (1979) Cockroach cause of allergic asthma. Its specificity and immunologic profile. J Allergy Clin Immunol 63: 80-86.

34. Rabito FA, Carlson J, Holt EW, Iqbal S, James MA (2011) Cockroach exposure independent of sensitization status and association with hospitalizations for asthma in inner-city children. Ann Allergy Asthma Immunol 106: 103-109.

35. Pola J1, Zapata C, Valdivieso R, Armentia A, Subiza J, et al. (1988) Cockroach asthma: case report and literature review. Allergol Immunopathol (Madr) 16: 61-65

36. Kanchongkittiphon W, Gaffin JM, Phipatanakul W (2014) The indoor environment and inner-city childhood asthma. Asian Pac J Allergy Immunol 32: $103-110$.

37. Slater JE, James R, Pongracic JA, Liu AH, Sarpong S, et al. (2007) Biological potency of German cockroach allergen extracts determined in an inner city population. Clin Exp Allergy 37: 1033-1039.

38. Jeong KY, Hongb CS, Yong TS (2006) Recombinant allergens for diagnosis and immunotherapy of allergic disorders, with emphasis on cockroach allergy. Curr Protein Pept Sci 7: 57-71.

39. Matsui EC (2013) Environmental control for asthma: recent evidence. Curr Opin Allergy Clin Immunol 13: 417-425.

40. Eggleston PA, Wood RA, Rand C, Nixon WJ, Chen PH, et al. (1999) Removal of cockroach allergen from inner-city homes. J Allergy Clin Immunol 104: 842 846.

41. Williams LW, Reinfried P, Brenner RJ. Cockroach extermination does not rapidly reduce allergen in settled dust. J Allergy Clin Immunol. 1999; 104(3 Pt 1):702-3.

42. Robertson BD, McCoy RL, Nelson MR, Haymore BR (2011) Effect of allergen immunotherapy practice parameters on cat extract prescribing patterns, 1993-2009. Ann Allergy Asthma Immunol 107: 437-440.

43. Platts-Mills TA, Vervloet D, Thomas WR, Aalberse RC, Chapman MD (1997) Indoor allergens and asthma: report of the Third International Workshop. $J$ Allergy Clin Immunol 100: S2-24.

44. Cox L, Esch RE, Corbett M, Hankin C, Nelson M, et al. (2011) Allergen immunotherapy practice in the United States: guidelines, measures, and outcomes. Ann Allergy Asthma Immunol 107: 289-299.

45. Portnoy J, Chew GL, Phipatanakul W, Williams PB, Grimes C, et al. (2013) Joint Task Force on Practice Parameters. Environmental assessment and exposure reduction of cockroaches: a practice parameter. J Allergy Clin Immunol 132: 802-808.

46. Kang BC, Johnson J, Morgan C, Chang JL (1988) The role of immunotherapy in cockroach asthma. J Asthma 25: 205-218.

47. Srivastava D, Gaur SN, Arora N, Singh BP (2011) Clinico-immunologica changes post-immunotherapy with Periplaneta americana. Eur J Clin Invest 41: $879-888$.

48. Wood RA, Togias A, Wildfire J, Visness CM, Matsui EC, et al. (2014) Development of cockroach immunotherapy by the Inner-City Asthma Consortium. J Allergy Clin Immunol 133: 846-852. 